\section{Update on \\ peri-operative fluid therapy}

\section{Vicky Ford-Fennah}

Recently the approach to perioperative fluid therapy (IVFT) in cats and dogs has changed greatly, from that of a liberal approach to a more conservative, individualized and goal-directed approach. The aims of perioperative IVFT include:

\section{- Correcting/replacing normal losses}

- Replacing increased evaporative losses (dry anaesthetic gases and surgical sites - in the absence of significant haemorrhage)

- Supporting cardiovascular function

- Counteracting negative effects on homeostatic mechanisms maintaining appropriate distribution of total body water

- Counteracting negative effects of anaesthetic agents, for example, vasodilation

- Maintaining patent intravenous access

- Managementment of surgical haemorrhage.

The typical IVFT rates previously used were: surgical rate $10 \mathrm{ml} / \mathrm{kg} / \mathrm{h}$, non-surgical rate $5 \mathrm{ml} / \mathrm{kg} / \mathrm{h}$. Multiple human publications have found that liberal approach to IVFT was associated with worse patient outcomes. Negative effects include:

Increased body weight
Increased lung water
- Cocreased pulmonary function
- Reduced gastric mobility
- - Increased postoperative infection rates
- Positive fluid balance
- Decreased packed cell volume (PCV)
- Decreased total protein (TP)
- Decreased body temperature.

In 2013 AAHA/AAFA released the Fluid Therapy Guidelines for Dogs and Cat. Recommendations included a starting rate of $5 \mathrm{ml} / \mathrm{kg} / \mathrm{h}$ in dogs and $3 \mathrm{ml} / \mathrm{kg} / \mathrm{h}$ in cats, reducing by $25 \%$ each hour of anaesthesia if the patient is stable (see goals listed below), using a balanced isotonic solution. All fluid inputs should be considered within this rate, for example, continuous rate infusions. Particular care should be taken with patients with cardiovascular disease, and lower rates considered.

Prior to anaesthesia any fluid deficits or electrolyte and acid-base abnormalities should be addressed as far as possible to optimize tissue perfusion and thus oxygen delivery. Parameters or 'goals' can be used to guide this stabilization and assess fluid status during the perioperative period. These include:

- Pulse rate and quality

- CRT
- Mucous membrane colour

- Respiratory rate and effort

- Lung sounds

- PCV/TP

- Serum lactate

- Urine specific gravity

- Blood urea nitrogen

- Creatinine

- Electrolytes

- Blood pressure

- $\mathrm{SpO}_{2}$

- Venous and arterial blood gases

- Skin turgor

- Body weight

- Urine output

- Mental status

- Extremity temperature.

Along with monitoring the above, it is important to be aware of blood loss. It is advantageous prior to any surgical procedure with a significant haemorrhage risk or vulnerable patients (e.g. anaemic or small patients) to calculate their blood volume. Approximate values for this are $88 \mathrm{ml} / \mathrm{kg}$ in the dog and $66 \mathrm{ml} / \mathrm{kg}$ in the cat.

The other main change has been the decreased use of synthetic colloids. These were commonly used to manage perioperative hypotension and haemorrhage. A study compared $0.9 \%$ saline and hydroxyethyl starch, finding no significant haemodynamic difference. In addition, adverse effects have been reported in both veterinary and human patients with colloid use. This is an area that requires further investigation.

\section{KEY LEARNING OBJECTIVES}

- Have an understanding of the traditional perioperative fluid therapy rates compared to the latest guidance

- Understand the possible negative effects of excessive perioperative fluids

- Have an understanding of what parameters we can use to guide fluid therapy

\section{MULTIPLE CHOICE QUESTIONS}

1. What is the recommended starting IVFT rate for a healthy dog with a normal hydration status?
(A) $10 \mathrm{ml} / \mathrm{kg} / \mathrm{h}$
(C) $3 \mathrm{ml} / \mathrm{kg} / \mathrm{h}$
(B) $7 \mathrm{ml} / \mathrm{kg} / \mathrm{h}$
(D) $5 \mathrm{ml} / \mathrm{kg} / \mathrm{h}$

2. What is the recommended starting IVFT rate for a healthy cat with a normal hydration status?
(A) $10 \mathrm{ml} / \mathrm{kg} / \mathrm{h}$
(C) $3 \mathrm{ml} / \mathrm{kg} / \mathrm{h}$
(B) $7 \mathrm{ml} / \mathrm{kg} / \mathrm{h}$
(D) $5 \mathrm{ml} / \mathrm{kg} / \mathrm{h}$

3. After the first hour of IVFT under general anaesthesia, if the patient is cardiovascularly stable, by what percentage should the IVFT be reduced?
(A) $10 \%$
(C) $25 \%$
(B) $20 \%$
(D) $30 \%$ 